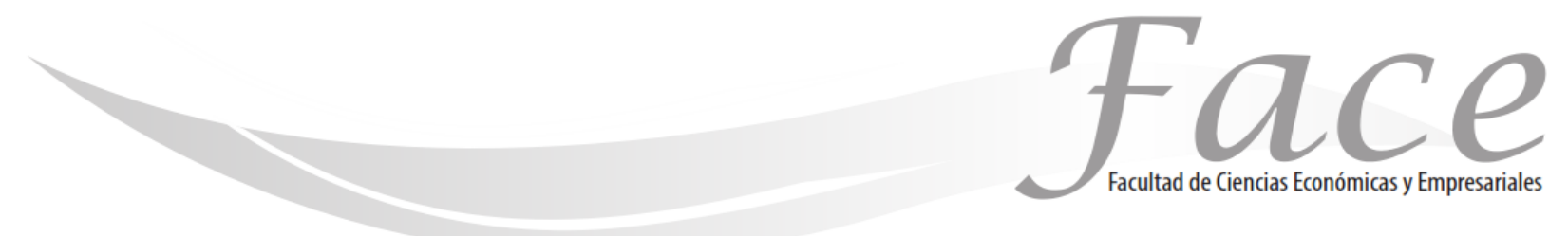

ISSN Impreso: 1794-9920

ISSN Electrónico: 2500-9338

Volumen $21-\mathrm{N}^{\circ} 1$

Año 2021

Págs. $136-154$

\title{
APROXIMACIONES REFLEXIVAS Y EMPÍRICAS EN LA GESTIÓN DE PROCESOS ADMINISTRATIVOS EN LAS MIPYMES DEL DEPARTAMENTO DE SUCRE- COLOMBIA
}

\author{
Elkin Darío Barios Pacheco * \\ https://orcid.org/0000-0002-1606-1700 \\ Luis Manuel Ortega Cardozo ** \\ https://orcid.org/0000-0001-7130-4712 \\ William A. Niebles Nuñez *** \\ https://orcid.org/0000-0001-9411-4583
}

Fecha de Recepción: Febrero 8 de 2021

Fecha de Aprobación: Mayo 27 de 2021

\section{Resumen:}

El presente texto tiene como finalidad analizar de manera reflexiva y empírica la gestión de procesos administrativos en las Mipymes del departamento de Sucre. Esto parte de la necesidad de una argumentación de un modelo de gestión que facilite de manera funcional y eficiente, los procesos administrativos en las Mipymes de Sucre. La metodología propuesta parte de un análisis teórico de los constructos de investigación, Gestión de procesos y en Mipymes, aplicando la bibliometría mediante el software VOSviewer. Para esta primera parte se trabajó con dos muestras bibliográficas de 14,333 documentos publicados sobre la gestión de procesos administrativos en base de datos SCOPUS, arrojando una muestra de 597 palabras claves de un total de 12748 palabras y 532 documentos publicados sobre el tema en Mipymes obteniendo una muestra de 47 palabras claves. El método aplicado es de lo general a lo particular, realizando las reflexiones a nivel general de la ciencia y luego particularizando en la Mipymes como abordaje teórico y anivel empírico en Sucre, Colombia. Entre los principales resultados se reconoce la gestión de los directivos o empresarios de las Mipymes en Sucre, identificando su idiosincrasia, prácticas comunes y formas de manejar situaciones problema. Por lo cual, el establecimiento de ventajas competitivas que le signifiquen un plus, inicia desde el cambio de paradigmas en su modelo de administración y gestión de procesos.

Palabras clave: : Gestión, modelo, técnicas, gerencia, ventaja competitiva, procesos administrativos

\footnotetext{
* Economista, Especialista en Gerencia de la Hacienda Pública, Maestrando en Administración de Empresas. Jefe de Departamento de Economía de la Universidad de Sucre- Colombia. Contacto: elkin.barrios@unisucre.edu.co

${ }^{* *}$ Administrador de Empresas, Especialista en Gerencia de la Calidad y Auditoria en Salud, Auditor interno ISO 9001:2015, Maestrando en Administración de Empresas. Jefe Departamento de Administración de la Universidad de Sucre. Contacto: Lmortegac@gmail.com

${ }^{* * *}$ Doctor en Ciencias Gerenciales, Magister en Dirección Estratégica, Administrador de Empresas. Docente de la Universidad de Sucre. Contacto: william.niebles@unisucre.edu.co
} 


\title{
REFLECTIVE AND EMPIRICAL APPROACHES IN THE MANAGEMENT OF ADMINISTRATIVE PROCESSES IN MSMES OF THE DEPARTMENT OF SUCRE - COLOMBIA
}

\begin{abstract}
:
The purpose of this essay is to analyze in a reflective and empirical way the management of administrative processes in the MSMEs of the department of Sucre. This is based on the need for an argumentation of a management model that facilitates, in a functional and efficient way, the administrative processes in the MSMEs of Sucre. The proposed methodology starts from a theoretical analysis of the research constructs, Process Management and in MSMEs, applying bibliometrics using the VOSviewer software. For this first part, we worked with two bibliographic samples of 14,333 documents published on the management of administrative processes in the SCOPUS database, yielding a sample of 597 keywords out of a total of 12,748 words and 532 documents published on the subject in MSMEs, obtaining a sample of 47 keywords. The method applied is from the general to the particular, making the reflections at a general level of science and then particularizing in the MSMEs as a theoretical and empirical approach in Sucre, Colombia. Among the main results, the management of the managers or entrepreneurs of MSMEs in Sucre is recognized, identifying their idiosyncrasies, common practices and ways of handling problem situations. Therefore, the establishment of competitive advantages that mean a plus, starts from the change of paradigms in its administration and process management model.
\end{abstract}

Keywords: : arrangement, model, techniques, management, competitive advantage, administrative processes.

\section{ABORDAGENS REFLETIVAS E EMPÍRICAS NA GESTÃO DE PROCESSOS ADMINISTRATIVOS EM MSMES DO DEPARTAMENTO DE SUCRE - COLOMBIA}

\author{
Resumo:
}

O objetivo deste ensaio é analisar de forma reflexiva e empírica a gestão dos processos administrativos nas MPMEs do departamento de Sucre. Isso se baseia na necessidade de uma argumentação de um modelo de gestão que facilite, de forma funcional e eficiente, os processos administrativos nas MPMEs de Sucre. A metodologia proposta parte de uma análise teórica dos construtos da pesquisa, Gestão de Processos e em MPMEs, aplicando bibliometria por meio do software VOSviewer. Para esta primeira parte, trabalhamos com duas amostras bibliográficas de 14.333 documentos publicados sobre gestão de processos administrativos na base de dados SCOPUS, resultando em uma amostra de 597 palavras-chave de um total de 12.748 palavras e 532 documentos publicados sobre 0 assunto em MPMEs, obtendo-se uma amostra de 47 palavras-chave. 0 método aplicado é do geral ao particular, fazendo as reflexões em um nível geral da ciência e depois se particularizando nas MPMEs como abordagem teórica e empírica em Sucre, Colômbia. Entre os principais resultados, destaca-se a gestão dos gestores ou empresários das MPMEs de Sucre, identificando suas idiossincrasias, práticas comuns e formas de lidar com situações problemáticas. Portanto, 0 estabelecimento de vantagens competitivas que significam um plus, parte da mudança de paradigmas no seu modelo de gestão e gestão de processos.

Palavras-chave: arranjo, modelo, técnicas, gestão, vantagem competitiva, processos administrativos. 


\section{Aproximación De La Evolución Conceptual De Gestión De Procesos}

La gestión y dirección de empresas, a principios del siglo XX, se orientaba a los aspectos técnicoproductivos y al diseño eficiente de los procesos administrativos. Estaban ligados a la escuela clásica, neoclásica (empírica) aupada por los aportes de la escuela de las relaciones humanas. Barnard con el sistema social y Simon con el comportamiento administrativo revolucionarían en la Dirección de Empresas los aspectos financieros y de comportamiento de las organizaciones. En los años 60 se establece con fuerza el Management Science (planificación y control) bajo la influencia de la escuela de sistemas.

Tal es la importancia de las Mipymes en el motor económico de un ente territorial y por extensión, de un país, que su aporte a la producción, a la generación de empleo y al fortalecimiento de los tejidos social y económico, representan un alto porcentaje del valor monetario de la producción de bienes y servicios de demanda final de un estado (PIB). No obstante, es inquietante observar que el ciclo de vida en este tipo de organizaciones en términos generales no es muy longevo, debido a problemas, muchas veces externos a ellas, por ejemplo, de mercado, del entorno económico, entre otros.

En los problemas relacionados con la gestión de las Mipymes, sobresalen la falta de cualificación, poca innovación y desarrollo tecnológico como los principales problemas asociados a los sobrevinientes del ambiente externo. Esta situación, hace necesario el estudio y establecimiento de modelos de administración que faciliten la interacción con el entorno y ayuden a identificar factores diferenciales que le impriman un valor agregado a la organización, volviéndola productiva y competitiva. En razón a ello, es ineludible conocer la gestión que manejan ya que su forma de existencia hace difícil un acompañamiento de parte del estado, a pesar de las iniciativas creadas para su fomento, lo que nos lleva proponer programas esquemáticos orientados a resolver sus problemas de gestión.
Seguido se da el gran auge del Marketing, al diseño de planes estratégicos con la formulación de estrategias para mejorar y defender la posición competitiva de la empresa. Ya en los 80 se presenta un proceso directivo, basado en el paradigma estratégico, que es conocido como Dirección estratégica. Con relación a la estrategia documentada y procesada en el mundo empresarial en los años sesenta del siglo XX, parte de la mano de Chandler quien la fijó como base para determinar las metas y los objetivos de una empresa junto con los recursos para conseguirlos (Chandler., 1962). Ansoff (1965), se refiere a la estrategia como el hilo conductor entre la empresa y las actividades que generan productos y por su parte Porter $(1980,1985$, 1996) establece que es necesaria la búsqueda de una posición competitiva.

En la década de los 90's según la teoría de recursos y capacidades (Barney, 1991; Grant, 1991) se establece que las organizaciones son capaces de desarrollar habilidades, capacidades y destrezas que aunado a los recursos facilitan la generación de estrategias de la cual se espera permita lograr los propósitos propuestos (Hitt et al., 2008). La estrategia de las cinco $\mathrm{P}$, marca el conjunto de aproximación estratégica de elementos empresariales (Mintzberg et al., 1997) quien además modela diez enfoques distintos en la formación de estrategia (Mintzberg et al, 1998) 
Por su parte, en la literatura sobre la gestión del conocimiento prima más los enfoques teóricos que las aportaciones prácticas. No obstante, se reconoce que el recurso humano y el conocimiento son la técnica efectiva de gestión, para la organización (Carro Suárez \& Orozco Silva, 2002). Identificando el conocimiento tácito y explícito. Donde, según Nonaka \& Takeuchi (1999) el conocimiento tácito propiedad individual y particular, mientras que el conocimiento explícito se puede expresar 0 representar mediante símbolos físicamente almacenables y transmisibles. Por otro lado, también se encuentra el modelo de Kaplan y Norton que tratan la identificación de necesidades y la toma de decisiones (Kaplan \& Norton, 1996), así como el modelo Technology Broker, Canadian Imperial Bank y Skandia Navigator, entre otros.

En cuanto a la gestión de calidad, que es otra de las aristas teóricas de la gestión de procesos, es de vital importancia para la mejora continua de los procesos, establecimiento de estándares y en base a mediciones estandarizadas, ajustado a un conocimiento basado en la realidad del contexto. La calidad puede ser entendida como el grado predecible de cumplimiento de requisitos y de costo satisfactorio del mercado (Deming, 1986) o la adecuación de un producto o servicio al uso (Juran, 1990), sin embargo, son muchas las percepciones de este concepto, pero coinciden en la importancia del mejoramiento continuo y del cliente.

Desde la perspectiva de la dirección estratégica, Foss (1997) establece la relación entre las características internas de la empresa y su posicionamiento competitivo en el mercado, para lo que admite dos hipótesis básicas: (a) existen diferencias sistemáticas entre las empresas según la utilización de sus recursos para implantar las estrategias y (b) estas diferencias son relativamente estables. La presencia de la Mipyme en el ámbito mundial reseña su capacidad de establecerse en diferentes entornos aprovechando oportunidades de negocio dado su tamaño y flexibilidad (Max-Neef, 1998) siendo generadora de fuentes de trabajo (Hernández \& Saavedra, 2008) muchas veces con poco capital (Tunal, 2003).

\section{METODOLOGÍA}

Para logar los propósitos del presente estudio, se empleó la revisión documental como método de análisis dentro de la metodología cualitativa, los cuales son recomendados por autores como Garita (2017) y, Binda y Balbastre (2013), porque representa una herramienta adecuada cuando se quieren analizar estudios socio-económicos, así como también, fenómenos de actividades productivas o tecnológicas. También, porque las recolecciones de información estructurada extraídas de fuentes bibliográficas facilitan el cumplimiento de objetivos reflexivos y descriptivos, que es lo que se pretende en este documento

De acuerdo con lo planteado por García, García, González, Carvalho y Catarreira (2016), se trianguló toda la información obtenida de la bibliografía respecto a las MIPYMES aplicando la bibliometría mediante el software VOSviewer, los datos se presentan a manera de ilustraciones para facilitar al lector el análisis de las variables que se tomaron. El estudio partió de lo general a lo particular, realizando las reflexiones a nivel general de la ciencia y luego particularizando en la Mipymes.

\section{RESULTADOS:}

\section{Orientación de las Investigaciones en gestión de procesos en Publicaciones Científicas}

Consultando la base de datos de SCOPUS 2021, existen un total de 14,333 documentos publicados sobre la gestión de procesos administrativos, siendo su máximo pico de publicación en 2008, con 1108 artículos (gráfico 1). Actualmente en 2021, en lo que va de año, ya se han publicado 209 artículos. Aunque la curva muestra una tendencia decreciente a partir de 2016 sigue resultando un tema de interés en la comunidad científica. 
Gráfico 1

Tendencia de publicaciones de alto impacto sobre la gestión de procesos administrativos

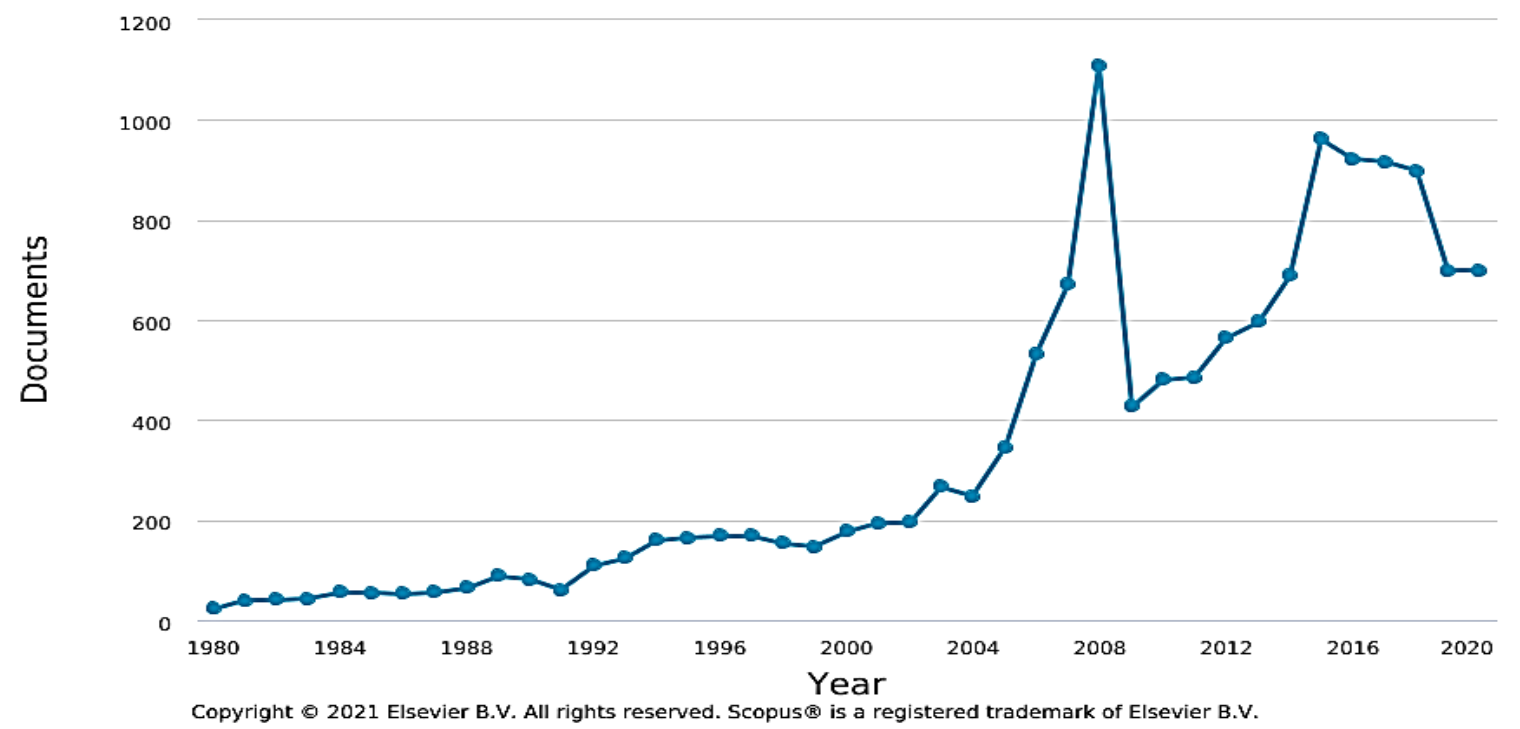

Fuente: Base de datos SOCPUS 2021

Tal es su importancia, que los 15 países que más publican al respecto tienen de 250 a 3400 artículos, destacándose, Estados Unidos (gráfico 2). En América Latina, solo resalta Brasil, con 384 publicaciones, resultado que indica la necesidad de realizar más investigaciones sobre este tema en el resto de los países latinos. En el caso específico de Colombia se han publicado 120 artículos en Scopus sobre el tema iniciando en 1999 (gráficos 3 y 4), siendo las universidades de Antioquia y Simón Bolívar, las de mayor participación 


\section{Gráfico 2}

Publicaciones de alto impacto sobre la gestión de procesos administrativos por países

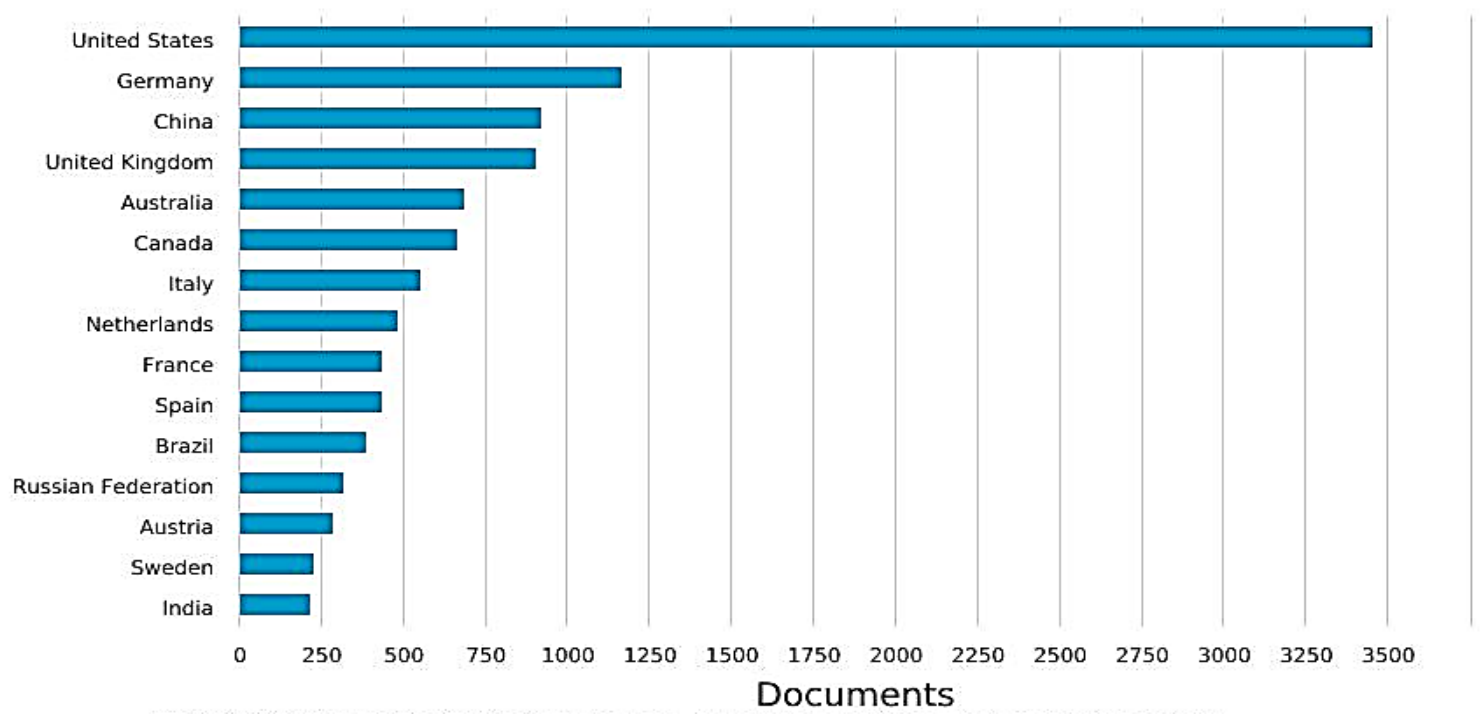

Fuente: Base de datos SOCPUS 2021

\section{Gráfico 3}

Tendencia de publicaciones de alto impacto sobre la gestión de procesos administrativos en Colombia

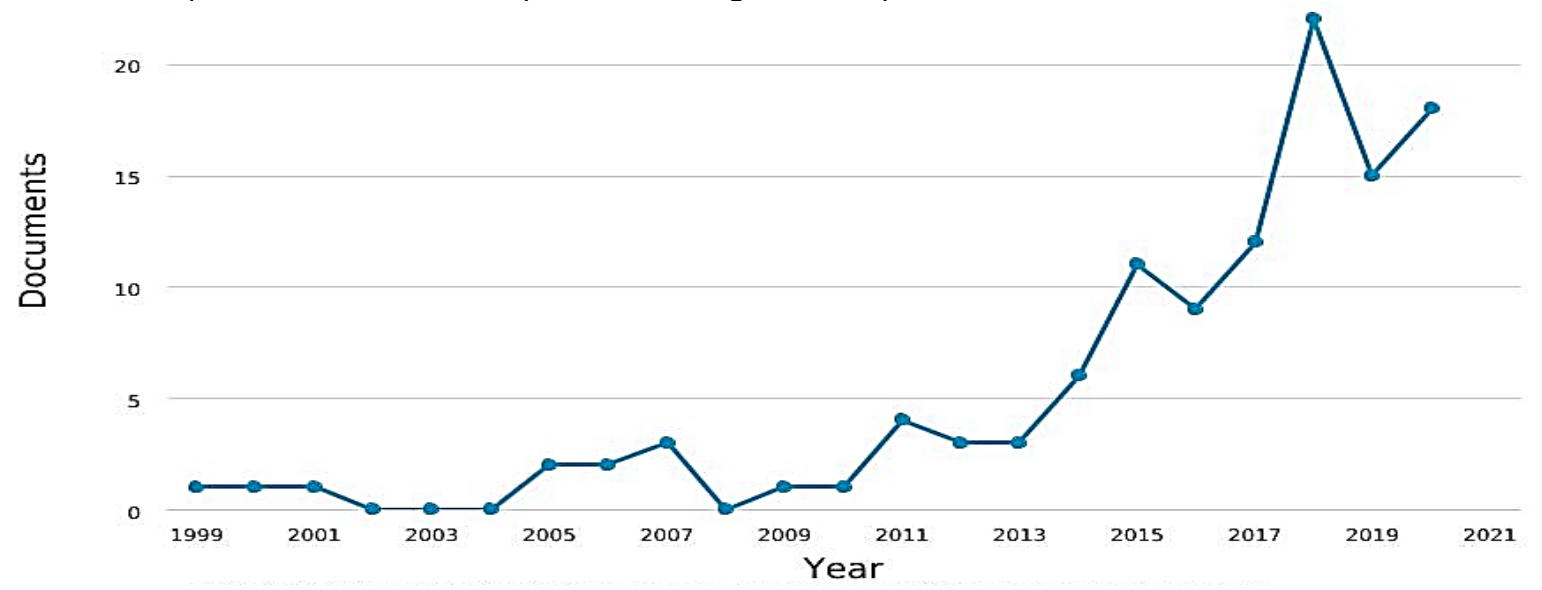

Fuente: Base de datos SOCPUS 2021 


\section{Gráfico 4}

Principales universidades colombianas que publican sobre el tema

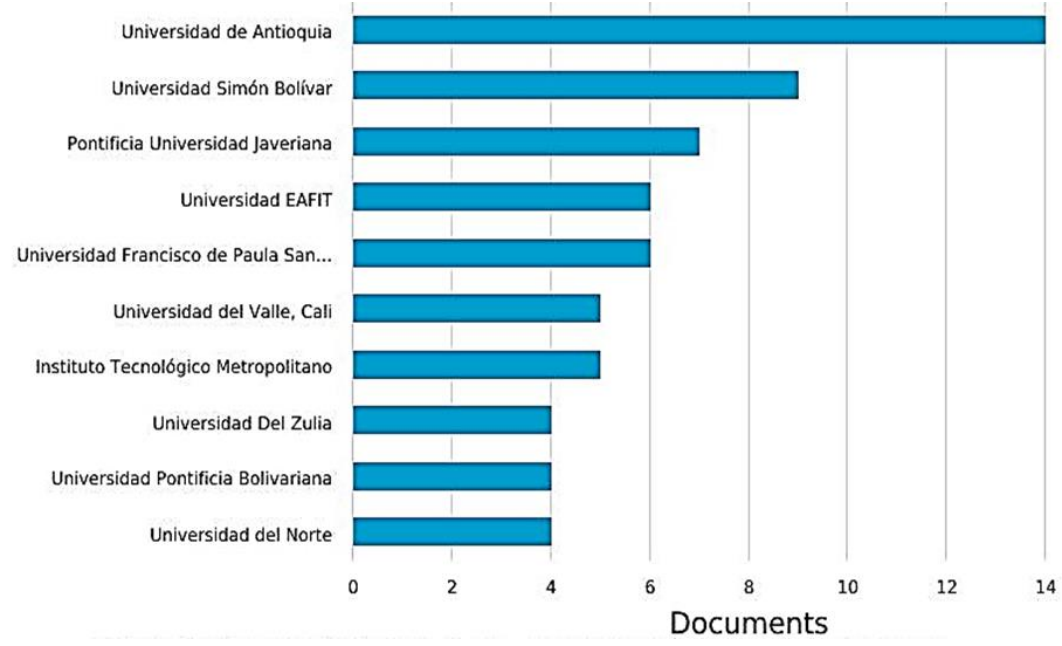

Fuente: Base de datos SOCPUS 2021

Cabe destacar que este resulta un tema multidisciplinar que no solo ha sido tratado en la administración sino en otras áreas de conocimiento, y un ejemplo es la distribución de estas publicaciones colombianas en cuanto a porcentajes por las diferentes áreas (gráfico 5), aunque ciencias sociales (22\%) y negocios (14\%) son las principales.

\section{Gráfico 5}

Porcentaje de publicaciones por área de conocimiento en Colombia.

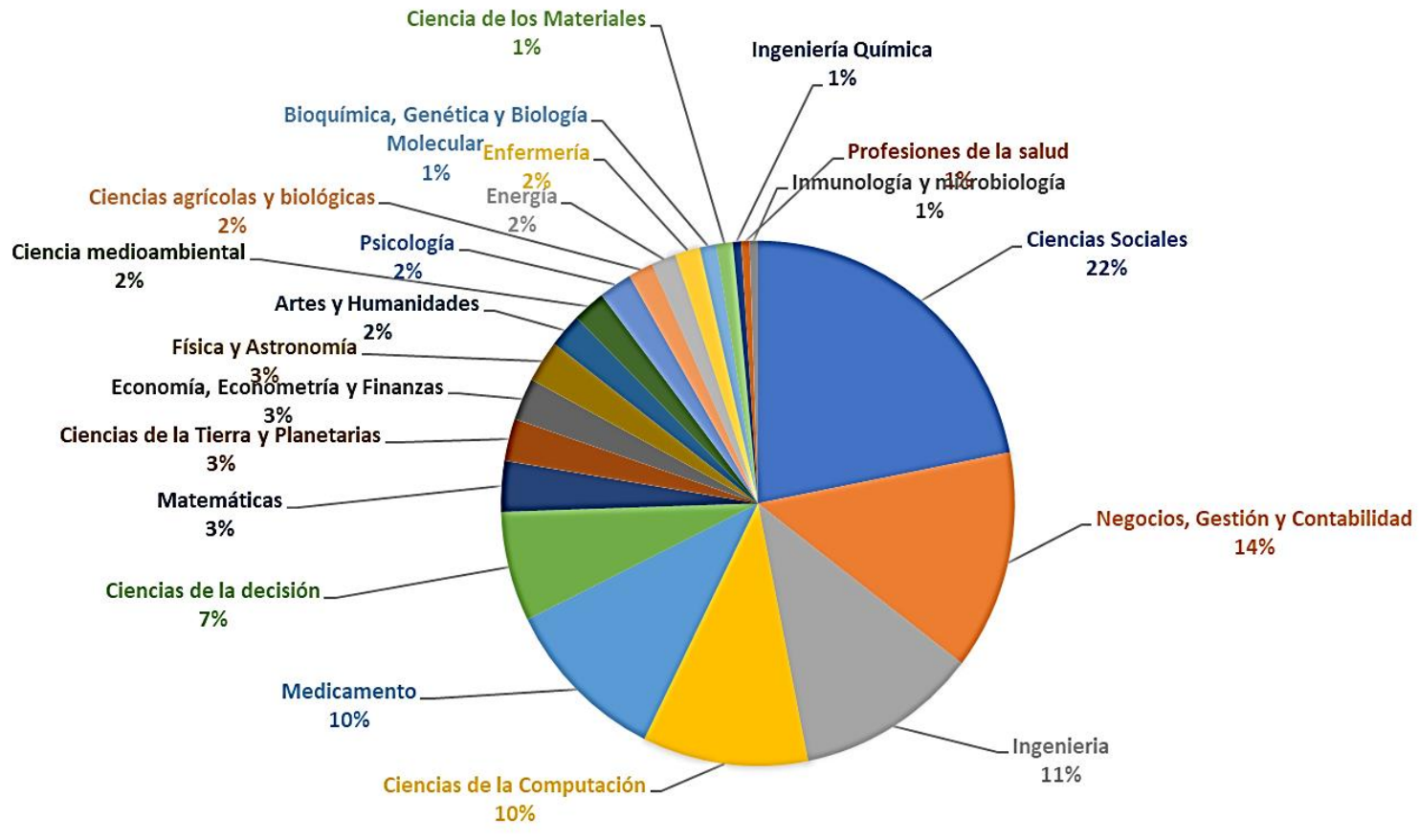


En un análisis bibliométrico más detallado procesando la base de datos inicial de 14333 artículos de Scopus, mediante el software VOSviewer, utilizando el método de co-ocurrencia de palabras claves, y un número mínimo de 10 citaciones (ocurrencias) se obtiene una muestra de 597 palabras claves de un total de 12748 palabras. Tal como se muestra en la figura 1, las redes de citaciones de dichas palabras exponen la presencia de cuatro clústeres, cuya mayor densidad está en la organización y gestión, procesamiento de datos administrativos, mejora de la calidad y gestión de recursos administrativos.
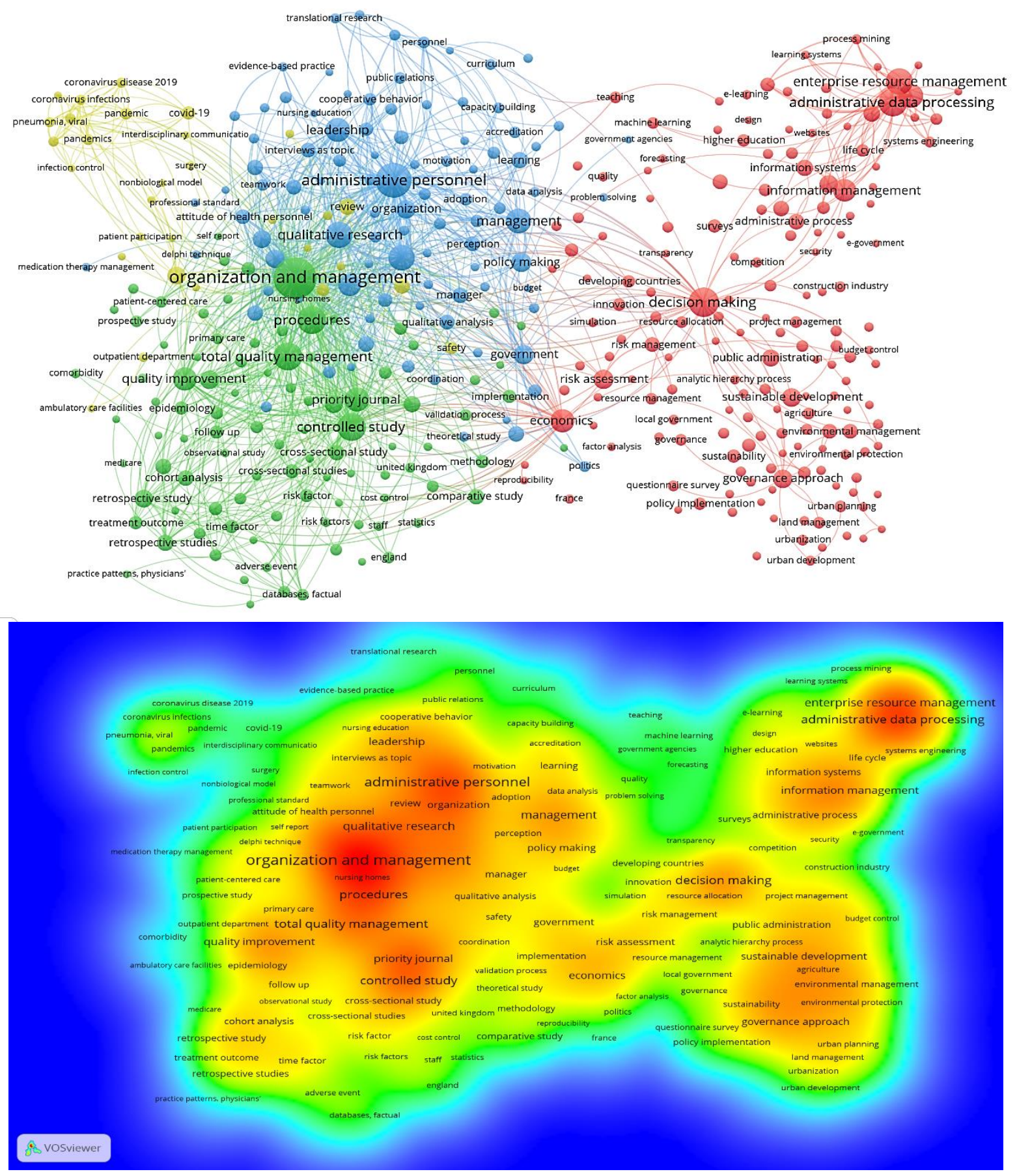

Figura 1. Network y Densidad de palabras claves de publicaciones de alto impacto sobre la gestión de procesos administrativos a nivel mundial Fuente: Base de datos SOCPUS 2021 procesada en VOSviewer 
A nivel de país, en Colombia, de los 120 artículos se generan 939 palabras claves de las cuales con 5 citaciones (ocurrencia) solo se obtienen 9 palabras claves, agrupadas en 2 clústeres (figura 2):

- Grupo 1: Latinoamérica, organización y gestión, humano (con mayor densidad), gestión, toma de decisiones.

- Grupo 2: Gestión de recursos empresariales, gestión del conocimiento (con mayor densidad), procesamiento de datos administrativos e innovación.
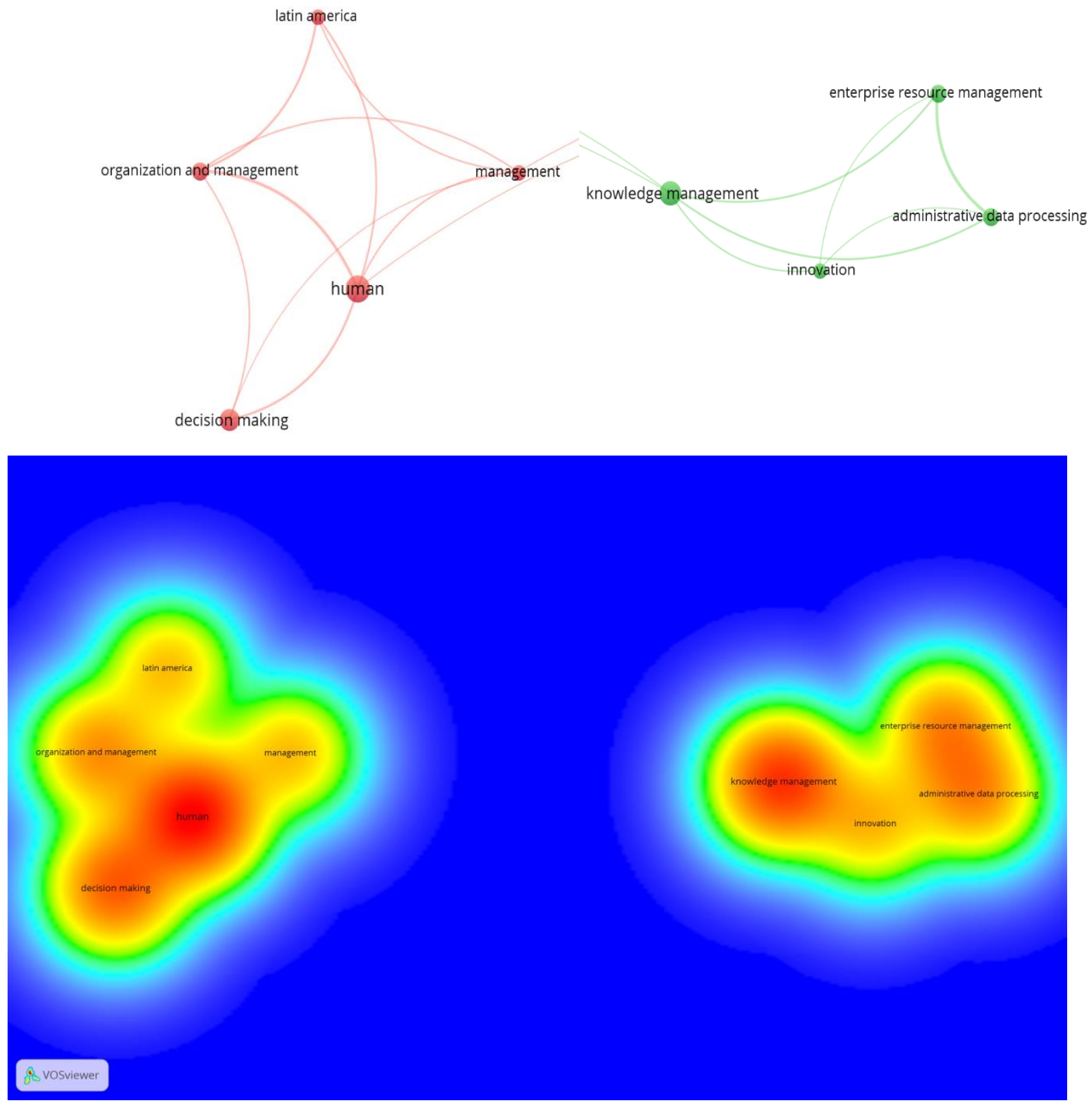

Figura 2. Network y Densidad de palabras claves de publicaciones de alto impacto sobre la gestión de procesos 


\section{Orientación de las investigaciones en gestión de procesos en Mipymes en publicaciones científicas}

La gestión de procesos administrativos de lleva a cabo, principalmente en el nivel empresarial y una de las clasificaciones contemporáneas son las micros, pequeñas y medianas empresas MIPYMES. Estas a nivel mundial, son un boom para el desarrollo y evolución de económica global. Es evidente que las pymes son el futuro del crecimiento y desarrollo económico dado que genera empleos, la producción y el comercio, principalmente minorista (Gálvez y García, 2012; Uccelatore, 2012). Su importancia radica en lo fundamental que son para el crecimiento y la creación de empleo en una economía. Según Saavedra \& Hernández (2008) las Mipymes aportan aproximadamente entre el $44 \%$ y $70 \%$ en la generación de empleo en países industrializados, $50 \%$ y $80 \%$ del empleo en los países en vía de desarrollo e industrializados, para según Baas e Schroorten (2006) representar un total del $90 \%$ de las empresas. En la Unión Europea, en particular, las Mipyme son importante para la competitividad de los países (Van Praag, e Versloot, 2007), ratificando así que estos segmentos representan un rol social y económico.
De este modo, el estudio de la gestión empresarial en estas organizaciones es relevante para el crecimiento y sostenibilidad de las mismas. Asi mismo, se destaca el hecho de que el existo no es solo producto de la gestión individual sino también de la asociación de organizaciones, como lo menciona Lozano (2010), "la experiencia internacional y nacional sugiere que la organización asociativa de micros, pequeñas y medianas empresas es una forma de competir eficaz y unificadamente con los mercados internacionales" (p. 178), soportada en una eficiente gestión organizacional. En referente a la gestión organizacional Fernández (2010) enfatiza basados en los conceptos de globalización de negocios y posicionamiento en los mercados, constituye un eje fundamental para la productividad, evolución y competitividad de las empresas.

Aplicando en este caso, la consulta a la base de datos de SCOPUS 2021, sobre el tema de MiPymes existen un total de 532 documentos publicados, siendo sus máximos picos de publicación en 2019 (71 artículos) y 2020 (67 artículos) (gráfico 6). En 2021, ya se han publicado 19 artículos sobre el tema en cuestión, lo cual al finalizar el año podría continuar el sentido creciente de la curva.

\section{Gráfico 6}

Tendencia de publicaciones de alto impacto sobre Mipymes

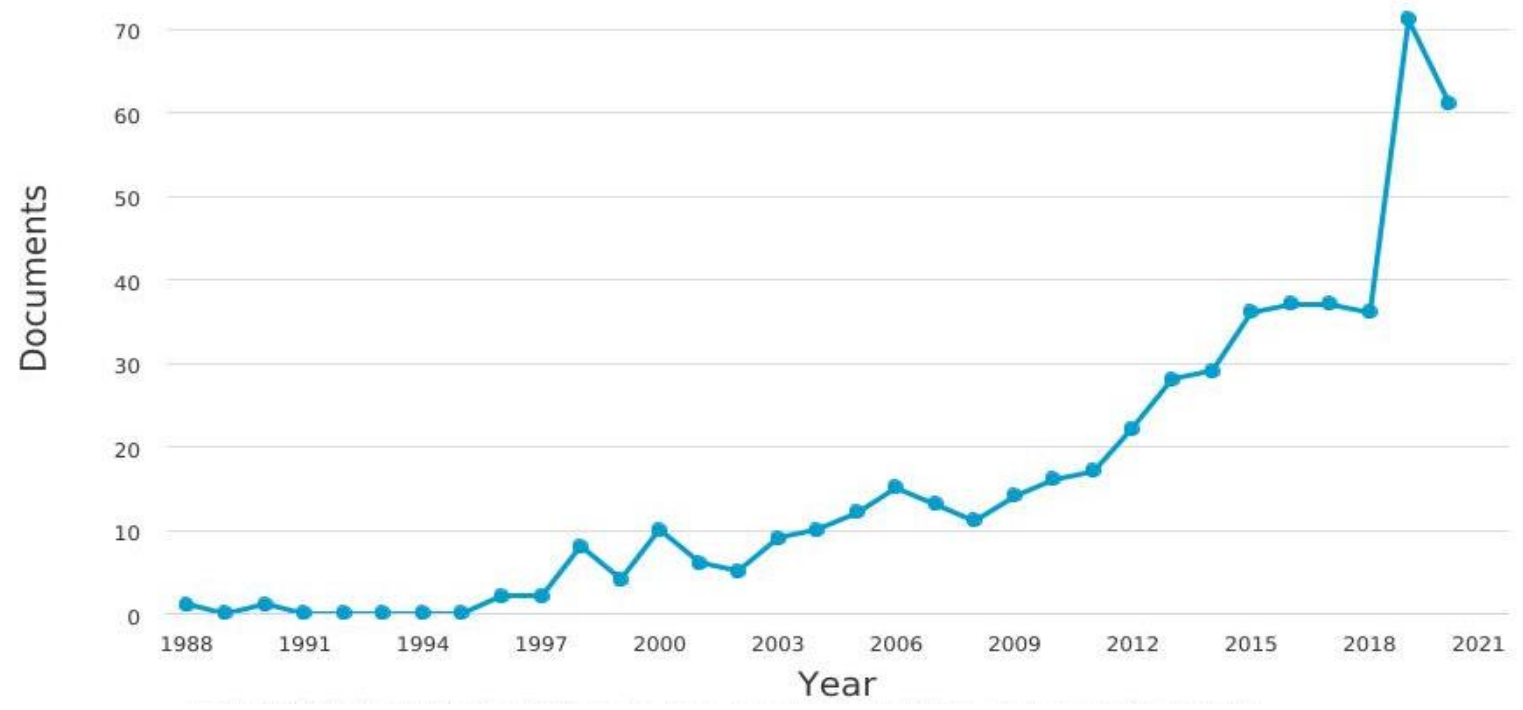

Fuente: Base de datos SOCPUS 2021 
En este término, Reino Unido supera a Estados unidos entre los 15 países que más referencia hacen sobre las microempresas (Gráfico 7). Como países latinoamericanos aparece entonces México.

Gráfico 7

Tendencia de publicaciones de alto impacto sobre MiPymes crear microempresas de residuos como una idea de negocio para muchos colombianos.

Pizarro Leongómez, (2002) hace una valoración critica del surgimiento de microempresas electorales. Al igual que la anterior es multidisciplinar en cuanto a las publicaciones colombianas en cuanto a porcentajes por las diferentes áreas (gráfico 7), aunque ciencias sociales (18\%) y negocios $(12 \%)$ son las principales.

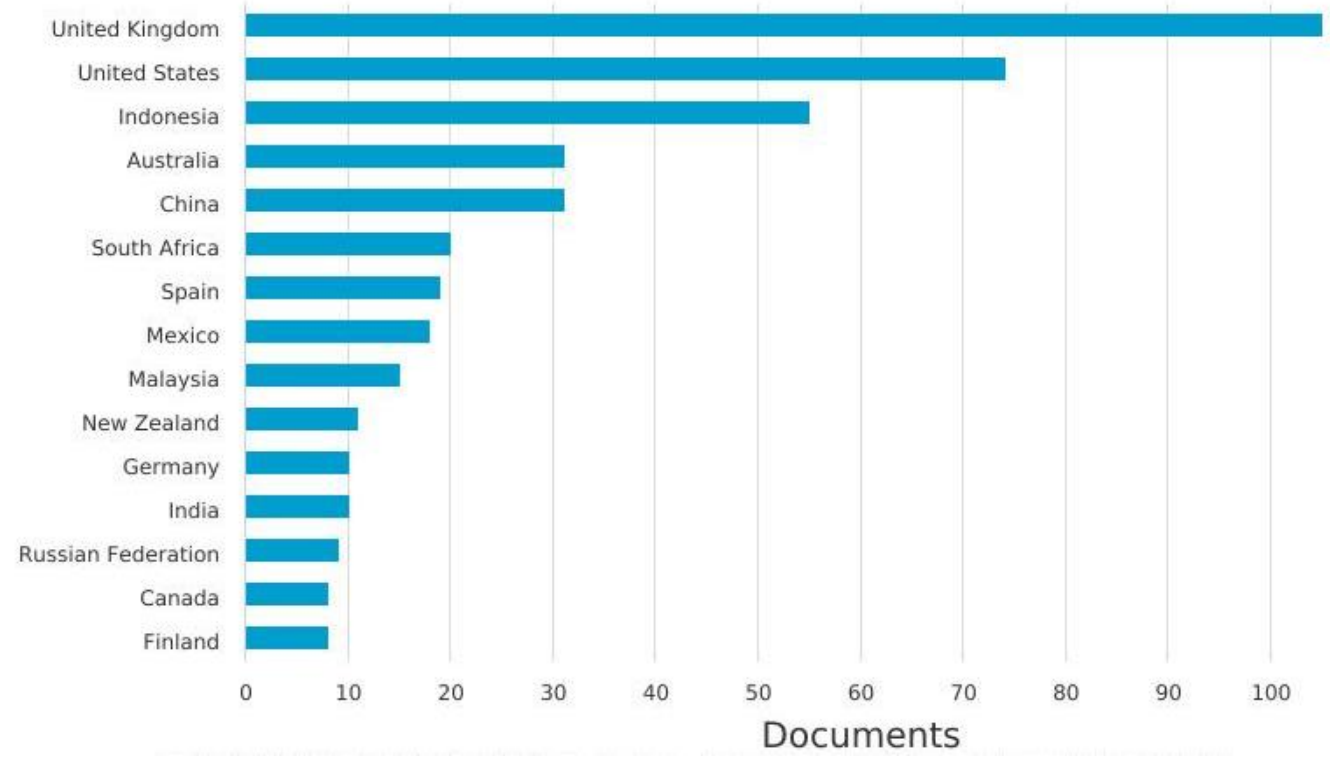

Fuente: Base de datos SOCPUS 2021

Abordando la temática en Colombia, a nivel de Scopus, Siendo la Universidad Pontifica Javeriana y la solo se relacionan seis artículos, lo que evidencia más Universidad Nacional las más importantes. que una falencia una oportunidad para el tratamiento a nivel científico, dado que está siendo poco tratado (gráficos 3 y 4). Los autores Aabrek, Forseth, BuenoLopez, y Molinas (2019) plantean como las microempresas pueden colaborar en la incorporación al país de las energías renovables. Eraso y Fontaine (2019), hacen énfasis en como este tipo de empresas contribuyen a la lucha contra la pobreza rural en Colombia. Por su parte, Mosquera-Laverde y Avendaño-Prieto (2018) demuestran la importancia de 


\section{Gráfico 7}

Porcentaje de publicaciones por área de conocimiento en Colombia.

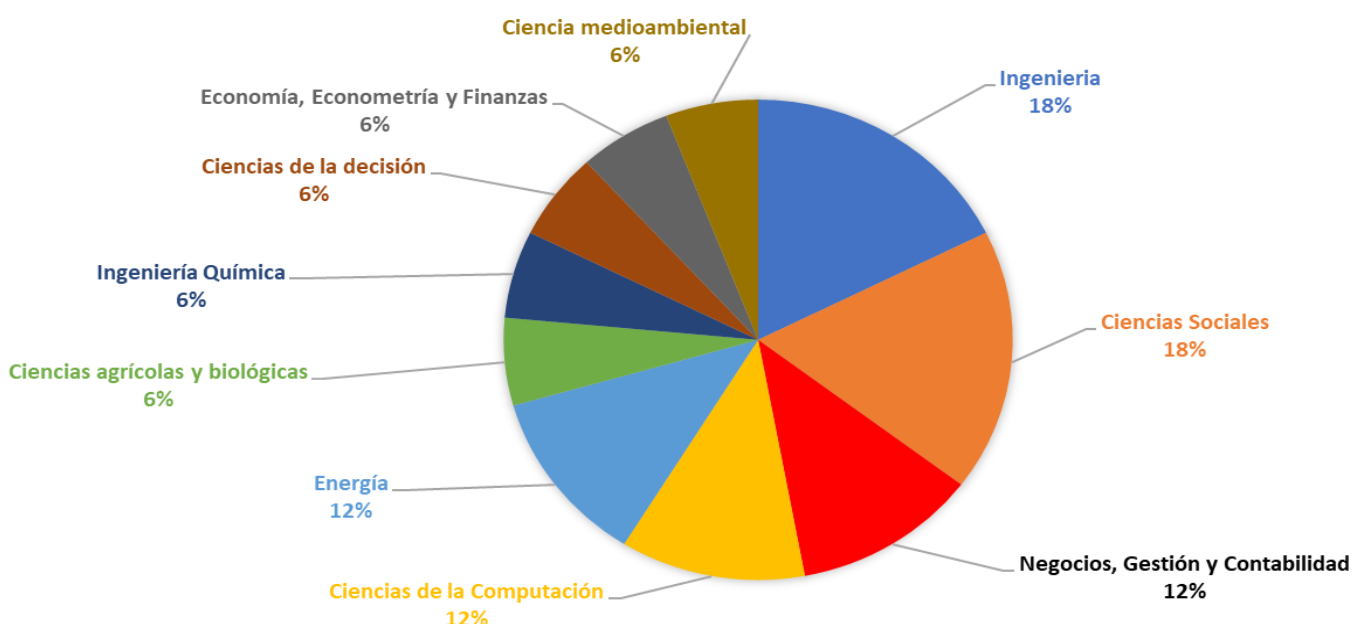

Fuente: Base de datos SOCPUS 2021

Gráfico 8

Principales universidades colombianas que publican sobre MIPYMES

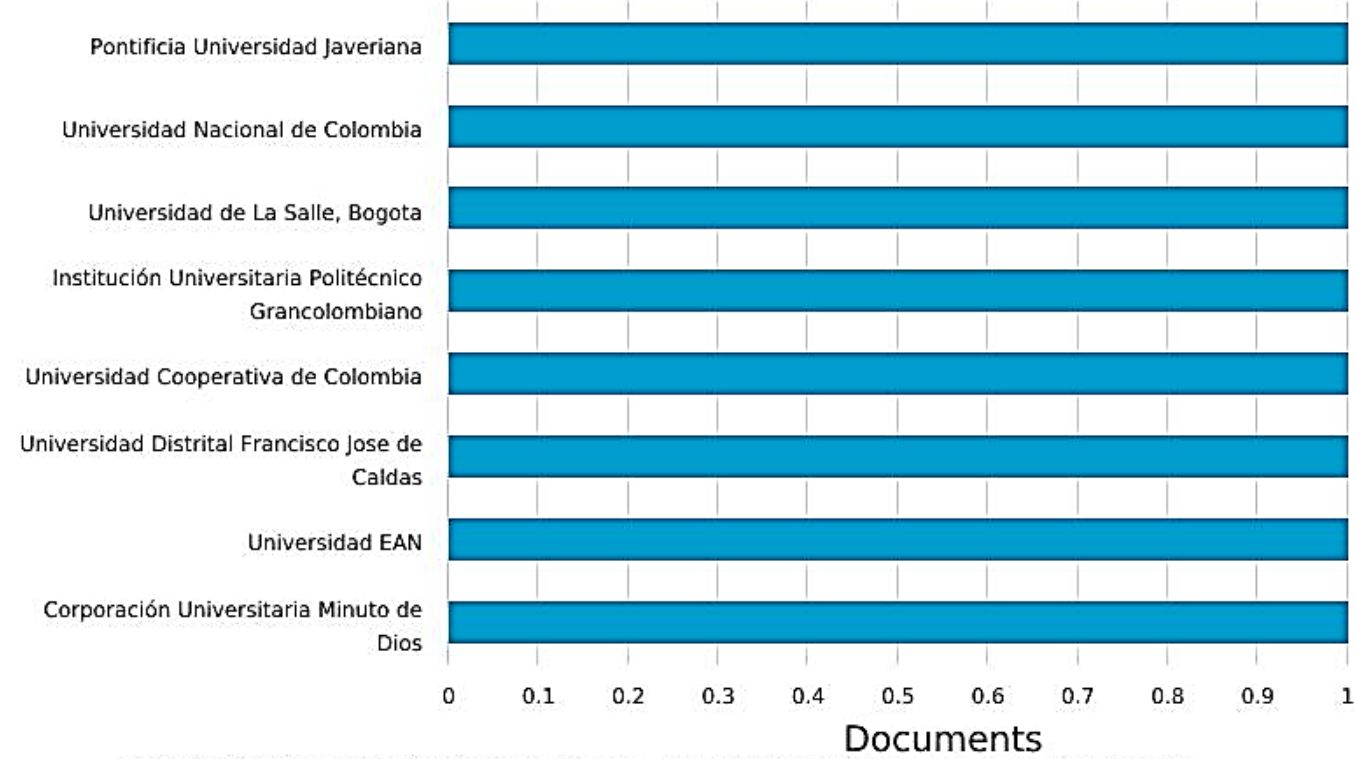

Fuente: Base de datos SOCPUS 2021

Ramírez (2011) ofrece una comprensión del comportamiento de los empresarios de micro y pequeñas empresas hacia la adquisición de información externa. Las universidades, cámaras de comercio y agencias gubernamentales locales pueden brindar asistencia desarrollando herramientas para realizar investigaciones del entorno comercial externo de las empresas, ayudándolas así a lograr una visión comercial más amplia a bajo costo. Esto se evidencia en el análisis bibliométrico de las publicaciones nacionales donde se obtuvieron 47 palabras claves y 2 clústeres (figura 3 ).

Grupo 1 (Rojo): Desarrollo económico

Grupo 2 (Verde) 
Pacheco Ruiz (2013) describe la estrategia en las Mipymes de Sincelejo y hace referencia de varios trabajos en Colombia relacionados a la Mipyme que estudiando estructura y formas de asociación

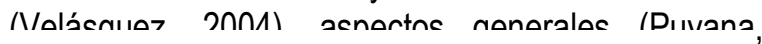
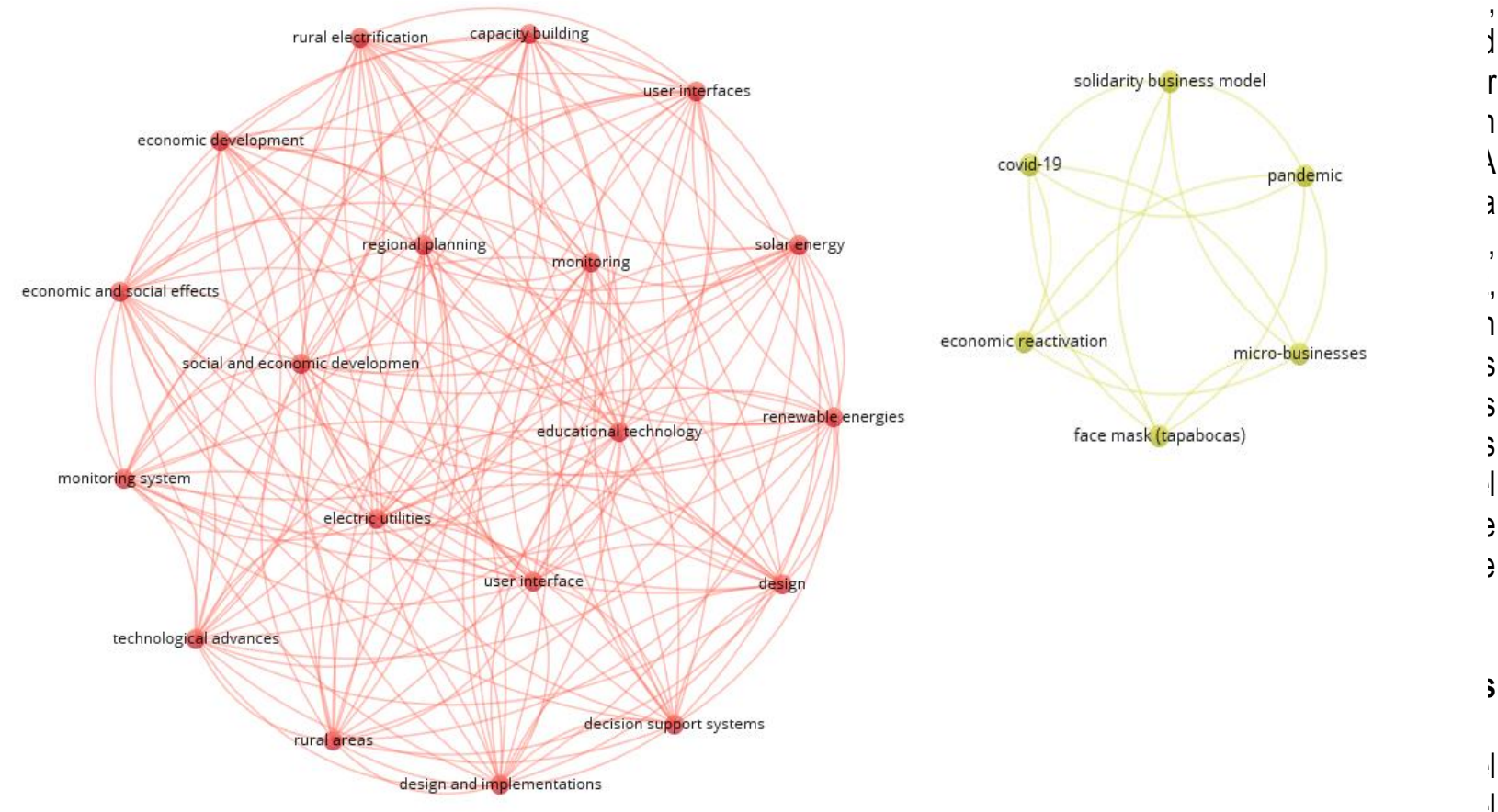

Figura 3. Network de palabras claves de publicaciones de alto impacto sobre MiPYMES en Colombia

Fuente: Base de datos SOCPUS 2021 procesada en VOSviewer

En Colombia la Ley Mipyme (Ley 590 de 2000 y Ley 905 de 2004 modificada) es quien regula este sector empresarial clasificándolo en micro, pequeñas, medianas y grandes empresas. La microempresa es la base de la pirámide empresarial, con un peso del $93 \%$ de las empresas del país y sumada a la Mipyme $6.5 \%$ de las empresas), son responsables del $66.4 \%$ del empleo nacional (PROPAIS, 2007). Es destacable que, entre las áreas de desempeño de las Mipyme, el comercio ocupa el renglón más importante, con un $54,66 \%$, seguido de servicios $(31,6 \%)$, el sector industrial $(12,22 \%)$ y otros (1,52\%) (Giraldo, 2007). que exige de sus actores una movilidad estratégica de recursos para el afianzamiento de resultados ya que la generación productiva reflejada en el PIB departamental referenciado con el nivel nacional muestra una proporción baja (0.73\%) (COMTS, 2012), teniendo en cuenta que se trata de un departamento con gente joven, en el que de su población (843.202 habitantes a 2014), el 70\% tiene hasta 40 años de edad (DANE, 2012), pero a su vez presenta una alta tasa de necesidades básicas insatisfechas, $46,6 \%$ y $22,67 \%$ de personas en situación de miseria. Además, Sincelejo, la capital del departamento, ocupa la penúltima posición entre las 22 ciudades capitales de departamento en cuanto al indicador global de competitividad (Observatorio del Caribe Colombiano, 2012). En Sucre, la Mipyme se esfuerza para desarrollar ventajas comparativas aprovechando los mercados locales, y una distribución de cuotas de mercado en un mercado limitado, con una importante tasa de mortalidad (en Sincelejo dejaron de operar 678 entre 2009 y 2012) lo que significa una necesidad no solo de establecerse y crecer sino también de sostenerse en el tiempo. 
La Mipyme presenta algunas características como el sistema de poder autoritario del empresario y la no diferenciación de las tareas que explican la poca visibilidad del control de gestión en este tipo de negocio, dicho de otro modo, la función de control de gestión en las Mipyme comúnmente se confunde con la función financiera y es tradicionalmente poco estructurado. Las Mipymes se enfrentan a una competencia cada vez más global y en este contexto, la rentabilidad de las empresas y su supervivencia depende de su capacidad de responder rápidamente y con flexibilidad. Esa es la razón principal por la que la gestión y dirección son elementos claves para lograr una ventaja competitiva. Estas tienen una importancia relevante para la economía de un país de organizar la producción, la generación neta de empleo y el proceso de renovación del tejido productivo. Estas razones justifican la necesidad de la creación de empresas Mipymes (Cardona \& Coronel de Renolfi, 2009).

Los estudios sobre las Mipymes se han caracterizado por mostrar problemas, muchas veces externos a ellas, por ejemplo, de mercado, del entorno económico, entre otros. Esta contribución sería más fácil de absorber si estas empresas tuvieran una gestión de procesos apropiada, es decir, si a nivel interno no presentara complicaciones. Por eso se hace necesario conocer sobre la gestión que manejan ya que su forma de existencia hace difícil un acompañamiento de parte del estado, a pesar de las iniciativas creadas para su fomento, y es posible que las Mipymes lo que necesiten sean programas o propuestas para resolver sus problemas de gestión.

Los estudios de los procesos de gestión pueden ayudar a explicar sus problemas y la posible solución, respetando las diferencias entre empresas de servicios, comerciales y manufactureras. Por otra parte, corresponde a las universidades el desarrollo de actividades de investigación y docencia que apoyen las iniciativas productivas departamentales como parte de su filosofía de crecimiento económico y social en actividades claves, apoyando además a las organizaciones en la construcción de una perspectiva para su actividad y consolidación.

En Sucre, según datos de la Cámara de Comercio de Sincelejo, en la capital se concentra el $74 \%$ de las Mipymes del departamento que igualmente registran como actividad principal el comercio, junto con actividades inmobiliarias, servicios sociales y de salud. Esto se traduce en un protagonismo del sector terciario de la economía, con una alta concentración en el sector servicios, pero no solo a nivel departamental sino nacional (COMTS, 2012). También el informe GEM (GEM, 2012) resalta que el abandono de las actividades empresariales se da por razones personales, problemas financieros y rentabilidad del negocio, parque tecnológico obsoleto.

Las empresas de la ciudad de Sincelejo no escapan de la complejidad a las cuales se ven avocadas las empresas colombianas, en el caso particular de las micro y pequeñas empresas del sector servicios, se ven inmersas a un contexto muy competitivo por la amplitud de la oferta y el enfoque económico de la ciudad a ese subsector de servicio, en el cual existe constante cambios micro y macro ambientales. Por esta razón, es fundamental que estas empresas unan esfuerzos 0 alineen su actividad mercantil para que el eje central de la gerencia se enfoque en la competitividad y la sociedad del conocimiento. (Villegas y Toro, 2009).

En este orden de ideas, Brune y Belzunegui (2000), expresan que las empresas familiares y Mipymes se deben acoplar a un mercado en red basado en la flexibilización de sus procesos para lograr menores periodos de fabricación con mayor calidad, menor tiempo de atención al consumidor, pero con producto ajustados a sus requerimientos de calidad, lo que ha conducido a la modernización de los procesos hasta tal punto que gradualmente se han estandarizado y automatizado

En este sentido, el efecto se ha notado en el Departamento de Sucre, la Mipymes presentan una tasa de mortalidad creciente, el $55 \%$ sobreviven al primer año, el $97,2 \%$ son empresas pequeñas con una base operativa inferior a los 10 trabajadores y se observa mucha informalidad (Pérez, 2011), esta situación pareciera afectar la economía de la ciudad de Sincelejo y del Departamento.

Por otra parte, Aznar Bellver, Cayo Araya, \& Cevallos Varela (2016), consideran que las MIPYMES no están separadas de su entorno, todo lo contrario, por tal razón, es fundamental analizar los aspectos internos y externos de las empresas, en especial, los que inciden notoriamente en la generación de valor, positiva 0 negativamente (cuadro 1). 


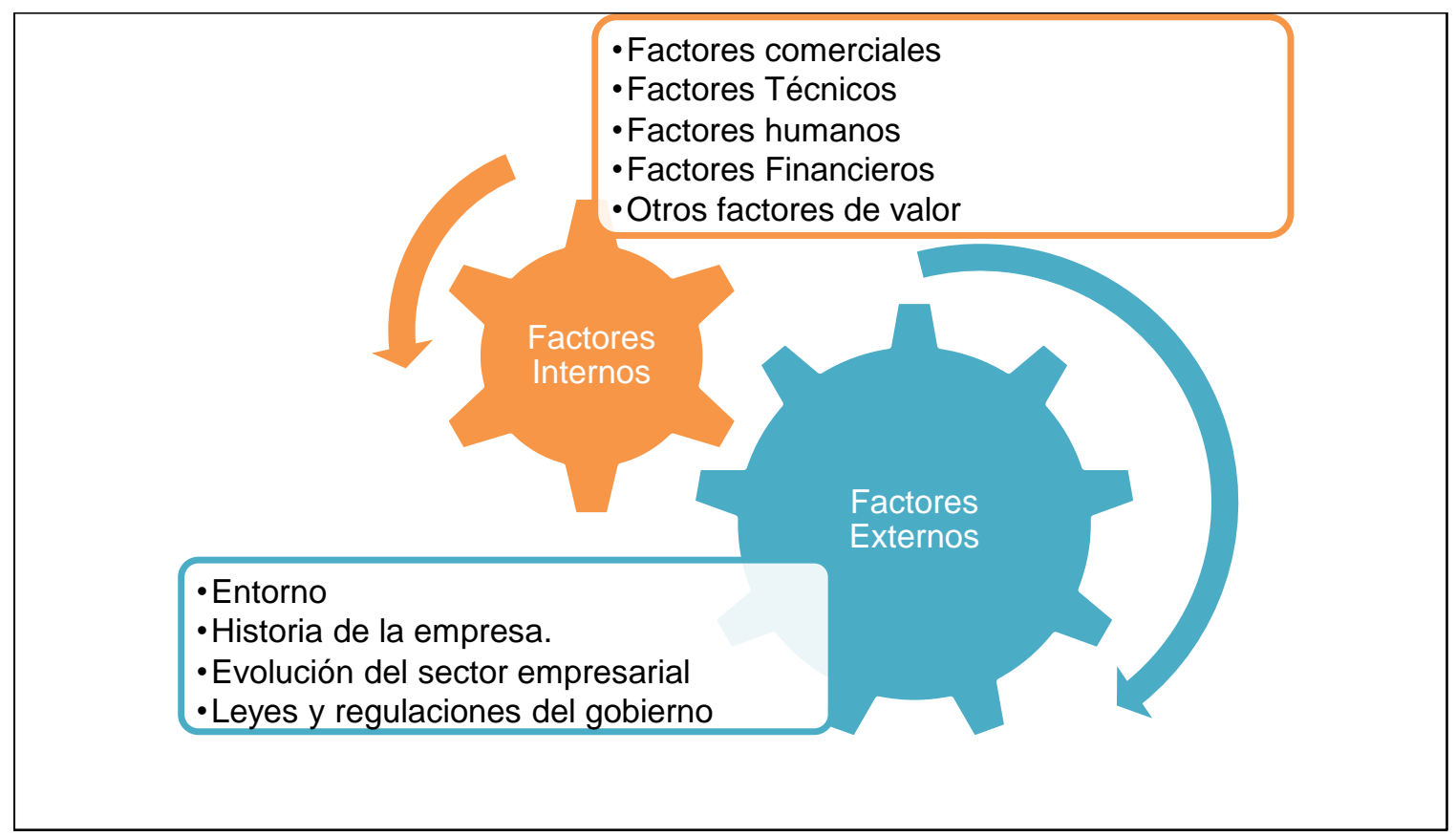

Cuadro 1. Clasificación de factores

Fuente. Basado en Aznar Bellver, Cayo Araya, \& Cevallos Varela (2016),

En consecuencia, en economías locales las MIPYMES juegan un papel preponderante, pues ellas son el fundamento de la actividad económica y tienen una incidencia en la oferta de servicios y generación de empleo. Su estudio, debe permitir entender la gestión que realizan en sus actividades gerenciales y el impacto que producen en sus entornos complejos.

Desde esta perspectiva, se denota que la gerencia de empresas en ambientes competitivos requiere del dominio de variables económicas que definen la estructura de mercado y las exigencias de escenarios complicados, lo que plantea la importancia de una gerencia estratégica. Aunque existen otros enfoques, como la teoría del caos, que facilitan la comprensión de los fenómenos organizacionales en ambientes complejos.
De esta manera, las MIPYMES deben estar abiertas a nuevos paradigmas, para adaptarse a los enfoques conceptuales que se generen de la transición de las teorías organizativas, de la teoría ambientalista (sistema abierto) a la teoría del caos y complejidad, que se caracterizan por presentar nuevas concepciones de las organizaciones que explican las dificultades de los nuevos escenarios económicos, una nueva metáfora (Morgan, 1986).

Al respecto, Morín (2007), concibe la complejidad como un conjunto de acciones, hechos, sucesos interacciones 0 determinaciones en el cual se enmarcan los mundos fenoménicos y que solo es percibido por sus dinámicas, así como en su adaptación. Aplicado al sector empresarial, ayuda a comprender a las organizaciones en los sistemas complejos, en el que medio ambiente juega un papel crucial en el propósito de adaptarse al mercado.

Así las cosas, comprender las teorías del cao y de la complejidad facilita el surgimiento de modelos más antirracionalistas que contribuyen al entendimiento de fenómenos que inciden en las empresas y que se alejan de los conceptos tradicionales que concebían a 
las organizaciones como equilibradas y estables, proponiendo nuevos paradigmas. Siendo reflexivos y de acuerdo con Peiró, (1993) para poder enfrentar estos nuevos retos y desafíos, se debe analizar los ambientes, ajustar los propósitos de las organizaciones a la racionalidad de la realidad, de manera que se produzcan de la conciencia del entorno y finalmente, buscar un ajuste organización - entorno, en procura de establecer las condiciones adecuadas que propicien el orden en la organización y coadyuven en su supervivencia.

\section{CONCLUSIONES}

La gestión de procesos administrativos continúa siendo una de las interrogantes fundamentales a nivel mundial e internacional. Su desarrollo y evolución preocupa a la comunidad científica que constantemente y de manera multidisciplinar busca soluciones que mejoren su aplicación. Tanto en Colombia como en el resto del mundo hay dos conceptos básicos que resaltan el procesamiento de datos administrativos y la organización y gestión. Otro de los conceptos a enfatizar y que en el país resultó de gran importancia, es el componente humano. Significa que independiente del avance tecnológico el carácter humano de la gestión de procesos juega un papel esencial en el éxito empresarial.

Las Mipymes del departamento, deben tener un cambio de paradigma en su esquema, dejando de lado el enfoque de administración operativo, de resolución de situaciones del día a día, carente de una planificación estratégica que direccione el rumbo de la organización; y asumir un enfoque de gestión por procesos, donde, a partir de un liderazgo efectivo y una hoja de ruta concertada y apropiada por partes interesadas, se desarrollen las actividades y tareas operativas, asumiendo a la organización como un sistema abierto que se adapta estratégicamente al entorno continuamente cambiante en gustos, deseos, anhelos y exigencias. Se pueden identificar los siguientes problemas: Falta de capacitación, cultura de innovación y desarrollo tecnológico.

Haciendo un análisis de Pareto, se identifica como punto crítico la falta de integración de los aspectos gerenciales, comerciales, productivos, financieros, tecnológicos, humanos y de evaluación y mejora. Haciendo intervención sistémica y efectiva en esos ejes, conllevaría a innovaciones permanentes, garantizaría la evolución continua y por consiguiente, altos niveles de competitividad y generación de valor, traducidos en una vida más longeva en el ecosistema empresarial.

\section{REFERENCIAS:}

Alcalá, J. L. (Noviembre de 2011). Las empresas de familia en la ciudad de Barranquilla y sus problemas de sucesión: Un enfoque desde la Teoría de la Agencia. Económicas CUC., 32(32), 185-198.

Ansoff, H. I. (1965). Corporate strategy. New York.: McGraw Hill.

Gálvez Albarracín, E. J., D García Pérez de Lema. (2012). Impacto de la innovación sobre el rendimiento de la MIPYME: un estudio empírico en Colombia

Barney, J. (1991). Firms Resources and Sustained Competitive Advantage. Journal of Management, 17, 99-120.

Baas T. e M. Schroorten. (2006). Relationship Banking and SMEs: Theoretical Analysis. Small Business Economics.

Binda, N. U. y Balbastre-Benavent, F. (2013). Investigación cuantitativa e investigación cualitativa: buscando las ventajas de las diferentes metodologías de investigación. Revista de Ciencias económicas, 31(2), 179-187

Blázquez, F., Dorta, J. A., \& Verona, M. C. (2006). Factores del crecimiento empresarial. Especial referencia a las pequeñas y medianas empresas. Innovar, 16(28), 43-56.

Cardona, G., \& Coronel de Renolfi, M. (2009). Tipificación de Mipymes Mediante Técnicas 
de Análisis Multivariado. El caso de la ciudad de Santiago. TEC Empresarial, 1-2.

Carro Suárez, J., \& Orozco Silva, E. (2002). Propuesta de estrategia para la introducción de la gestión de la información y la gestión del conocimiento en las organizaciones cubanas. Ciencias de la Información, 17-23.

Casas Ochoa, J., Guarín Rincón, H. O., Hurtado Bolaños, H., \& Villalba Benítez, M. (2013). Innovación en Mipymes artesanales de Morroa, Sucre, 2012. Económicas CUC, 1528.

Cayo Araya, T.; Aznar Bellver, J.; Cevallos Varela, D. (2016). Valoración de empresas. Métodos y casos prácticos para pequeñas y medianas empresas. Editorial Universitat Politècnica de València.

Chandler, A. D. (1962). Strategy and Structure: Chapters in the History of the Industrial Enterprise. Cambridge.: The MIT Press.

Chandler, A. D. (1992 ). Organizational Capabilities and the Economic History of the Industrial Enterprise. Journal of Economic Perspectives, 6(3), 79-100.

COMTS. (2012). Diagnostico del mercado laboral y perfil economico y productivo. Corporación Observatorio del Mercado de Trabajo en Sucre, Sincelejo.

DANE. (2012). Clasificación industrial internacional uniforme de todas las actividades económicas, Revisión 4 adaptada para Colombia, CIIU Rev. 4 A.C. Recuperado el 7 de Enero de 2013, de http://camara.ccb.org.co/documentos/11510_ ciiudane4.pdf

DANE. (2012). Proyecciones de población. Recuperado el 24 de junio de 2012, de http://www.dane.gov.co
Deming, E. (1986). Calidad, productividad y competitividad. La salida de la crisis. Cambridge UniversityPress.

E. J. Gálvez Albarracín, D García Pérez de Lema. (2012). Impacto de la innovación sobre el rendimiento de la MIPYME: un estudio empírico en Colombia. Estudios gerenciales, 28: 13-13.

Foss, N. J. (1997). Resources and strategy: A brief overview of themes and contributions. Resources, Firms and Strategies, 3-20.

Franco Ángel, M., \& Urbano Pulido, D. (2010). El éxito de las Mipymes en Colombia: Un estudio de casos en el sector salud. Estudios gerenciales, 77-97.

GEM. (2012). Global Entrepeneurship Monitor Colombia. Región Caribe 2011-2012. Barranquilla: Universidad del Norte.

E. J. Gálvez Albarracín, D García Pérez de Lema (2012). Impacto de la innovación sobre el rendimiento de la MIPYME: un estudio empírico en Colombia. Estudios gerenciales, 28: 13-13.

García, T., García, L., González, R., Carvalho, J. y Catarreira, S. (2016). Revisión metodológica de la triangulación como estrategia de investigación. CIAIQ 2016, 3.

Garita, R. B. (2017). La investigación cualitativa en las Ciencias de la Administración: aproximaciones teórico-metodológicas. Revista Nacional de Administración, 8(1), 2545.

Giraldo R., B. (2007). Estadísticas de la microempresa en Colombia: análisis comparativo 19902005.

Grant, R. (1991). The resource-based theory of competitive advantage: Implications for 
APROXIMACIONES REFLEXIVAS Y EMPIRICAS EN LA GESTIÓN DE PROCESOS ADMINISTRATIVOS EN LAS MIPYMES DEL DEPARTAMENTO DE SUCRE

Elkin Darío Barios Pacheco - Luis Manuel Ortega Cardozo - William A. Niebles Nuñez

strategy formulation. California Management Review, 33, 114-135.

Hernández , C. Y., \& Saavedra, G. M. (2008). Caracterización e importancia de las MIPYME en Latinoamérica: Un estudio comparativo. Revista actualidad contable FACES. 11(17), 122-134., 122-134.

Hitt, M., Ireland, D., \& Hoskisson, E. (2008). Administración estratégica: competitividad y globalización, conceptos y casos. México: Thompson.

Juran, J. M. (1990). Juran y el liderazgo para la calidad, manual para ejecutivos. Madrid: Ediciones Díaz de Santos.

Kaplan , R., \& Norton, D. (1996). Using the Balanced Scorecard as a Strategic Management System. Harvard.

Lozano, M. A. (2010). Modelos de asociatividad: estrategias efectivas para el desarrollo de las Pymes Revista EAN, 68: 178-178

Max-Neef, M. (1998). Desarrollo a escala humana: conceptos, aplicaciones y algunas reflexiones. Barcelona: Icaria.

Mintzberg, H., Ahlstrand, B., \& Lampel, L. (1998). Strategy Safari: A Guided Tour Through the Wilds of Strategic Management. New York,: Simon \& Schuster.

Mintzberg, H., Voyer, J., \& Quinn, J. (1997). El proceso estratégico. Conceptos, contextos y casos. México: Pearson Education. $1^{\text {a }}$ ed.

Morin, Edgar. (2007). Consideraciones básicas del pensamiento complejo de Edgar Morin, en la educación.

Montoya , R., \& Castellanos. (2010). Situación de la competitividad de las Mipyme en Colombia: elementos actuales y retos. Agronomía Colombiana, 28(1), 107-117.
Nonaka, I., \& Takeuchi , H. (1999). La organización creadora de conocimiento. Cómo las compañías japonesas crean la. México DF: Oxford University Press.

Observatorio del Caribe Colombiano. (2012). Indicador Global de Competitividad de las Ciudades del Caribe Colombiano. Evolución 2009-2010. Barranquilla.

Pacheco Ruiz, C. M. (2013). Estrategias empresariales más utilizadas por las Mipymes en Sincelejo. Económicas CUC, 183-202.

Peiró, José (1993). Desencadenantes del estrés laboral

Porter, M. (1980). Strategy competitive. New York: Free Press.

Porter, M. (1985). Competitive advantage. New York: The Free Press.

Porter, M. (1987). From Competitive Advantage to Corporate Strategy. Harvard Business Review.

Porter, M. (1996). What is strategy? Harvard Business Review, 74(6), 61-78.

PRC. (2008). Plan Regional de Competitividad de Sucre.

PROPAIS. (2007). Cómo enfrentar los nuevos desafíos. En: II Foro de la microempresa. Barranquilla.

Puyana, D. (Junio de 2004). La Mipyme y su situación en Colombia. Civilizar(6).

Radas, S., \& Bozic, L. (2009). The antecedents of SME innovativeness in an emerging transition economy. Technovation, 438-450.

Regalado H, R. (2007). 2002, las Mipyme en Latinoamérica. Estudios e Investigaciones en la Organización Latinoamericana de Administración. Latinoamérica. 
Sánchez Quintero, J. (2003). Estrategia Integral para Mipymes Innovadoras. Revista Escuela de Administración de Negocios, 47, 34-45.

Sarmiento, S., \& Jaimes Amorocho, H. (2003). Estrategias utilizadas por grandes empresas barranquilleras en el periodo 1995 - 2000. Universidad del Norte. Barranquilla: Universidad del Norte.

Tunal, G. (2003). El problema de clasificación de las microempresas. Actualidad Contable FACES, Año 6(7), 78-91.

Uccelatore, M. (2012). importancia y financiamiento de las pequeñas y medianas empresas. Cecreda.

Velásquez, F. (2004). La estrategia, la estructura y las formas de asociación: fuentes de ventaja competitiva para las Mipymes colombianas. Estudios Gerenciales, 73-97.

Vélez, D., Holguín, H., De la Hoz, G. D., Durán, Y., \& Gutiérrez, I. (2008). Dinámica de la empresa familiar Mipyme.

Fernández, Z., A Revilla. (2010). Hacer de la necesidad virtud: los recursos de las pymes Economía industrial, 375: 53-64

Aabrek, V., Forseth, I., Bueno-Lopez, M., \& Molinas, M. (2019). Design and implementation of a monitoring system for decision support in a micro-business based on solar energy microgrid in rural colombia. Paper presented at the GHTC 2018 - IEEE Global Humanitarian Technology Conference, Proceedings, doi:10.1109/GHTC.2018.8601571

Eraso, J. P. M., \& Fontaine, G. (2019). La participación ciudadana en la política de lucha contra la pobreza rural en colombia. Cuadernos Del Cendes, 36(100), 81-106.
Hernández Viveros, L. J., Murcia Rodriguez, J. C., \& López Sarmiento, D. A. (2020). Solidarity business model for micro-businesses that allows economic reactivation due to COVID19 in colombia. International Journal of Engineering Research and Technology, 13(11), 3795-3798.

Mosquera-Laverde, W. E., \& Avendaño-Prieto, G. (2018). Solid waste valorization strategy in bogota- colombia as a sustainable city component. Paper presented at the Proceedings of the International Conference on Industrial Engineering and Operations Management, , 2018(SEP) 870-876.

Pizarro Leongómez, E. (2002). The partisan atomization in colombia: The phenomenon of electoral micro businesses. [La atomización partidista en Colombia: El fenómeno de las micro-empresas electorales] Working Paper of the Helen Kellogg Institute for International Studies, (292)

Ramírez, A. C. (2011). Attitudes of micro and small business entrepreneurs towards the acquisition of external information for making business decisions. [Atitudes de empresários de micro e pequenas empresas perante a aquisição de informação externa para a tomada de decisões de negócio] Estudios Gerenciales, $\quad 27(121), \quad$ 159-173. doi:10.1016/S0123-5923(11)70186-3

Villegas y Toro (2006). Hacia la competitividad sistémica de las MIPYMES: un análisis del contexto colombiano.

Van Praag C. M. e P. H. Versloot. (2007). What is the value of entrepreneurship? A review of recent research. Small Business Economics, 351382. 